\title{
Dose and fractionation schedules in radiotherapy for non-small cell lung cancer
}

\author{
Lucyna Kepka, Joanna Socha
}

Department of Radiotherapy, Military Institute of Medicine, Warsaw, Poland

Contributions: (I) Conception and design: All authors; (II) Administrative support: None; (III) Provision of study materials or patients: None; (IV) Collection and assembly of data: All authors; (V) Data analysis and interpretation: All authors; (VI) Manuscript writing: All authors; (VII) Final approval of manuscript: All authors.

Correspondence to: Prof. Lucyna Kepka, MD, PhD. Department of Radiotherapy, Military Institute of Medicine, Szaserów Street 128, 04-141 Warsaw, Poland. Email: lkepka@wim.mil.pl.

\begin{abstract}
In the field of radiotherapy (RT), the issues of total dose, fractionation, and overall treatment time for non-small cell lung cancer (NSCLC) have been extensively investigated. There is some evidence to suggest that higher treatment intensity of RT, when given alone or sequentially with chemotherapy (CHT), is associated with improved survival. However, there is no evidence that the outcome is improved by RT at a higher dose and/or higher intensity when it is used concurrently with CHT. Moreover, some reports on the combination of full dose CHT with a higher biological dose of RT warn of the significant risk posed by such intensification. Stereotactic body radiotherapy (SBRT) provides a high rate of local control in the management of early-stage NSCLC through the use of high ablative doses. However, in centrally located tumors the use of SBRT may carry a risk of serious damage to the great vessels, bronchi, and esophagus, owing to the high ablative doses needed for optimal tumor control. There is a similar problem with moderate hypofractionation in radical RT for locally advanced NSCLC, and more evidence needs to be gathered regarding the safety of such schedules, especially when used in combination with CHT. In this article, we review the current evidence and questions related to RT dose/fractionation in NSCLC.
\end{abstract}

Keywords: Non-small cell lung cancer (NSCLC); radiotherapy (RT); total dose; radiotherapy fractionation

Submitted Feb 14, 2020. Accepted for publication Apr 15, 2020.

doi: $10.21037 /$ tlcr-20-253

View this article at: http://dx.doi.org/10.21037/tlcr-20-253

\section{Introduction}

Lung cancer is responsible for more deaths in the European Union than any other cancer (1). Radiotherapy (RT) plays a major role in the management of lung cancer. Based on the best available evidence, the proportion of lung cancer patients for whom RT is indicated is estimated to be $76 \%$ (2). Despite improving over the years, the survival rate for lung cancer is still very low, with a 5 -year survival rate of approximately $20 \%$ (3). Thus, a question has arisen regarding how the therapeutic ratio of RT in the management of lung cancer can be increased.

The combination of RT with concomitant chemotherapy (CHT) can improve the treatment outcome for patients with locally advanced non-small cell lung cancer (NSCLC) by increasing local control, leading to a subsequent increase in overall survival $(4,5)$. Efforts to further increase the effect of RT when given concurrently with CHT or as a sole treatment modality are justified. Such an increase may be achieved by escalating the dose of radiation. However, in concomitant RT-CHT, giving a higher dose of 74 Gy in 37 fractions was found to be detrimental for overall survival and local control compared with the standard $60 \mathrm{~Gy}$ in 30 fractions (6). The counterintuitive harmful effects of the higher radiation dose on the outcome in NSCLC may be attributed to several factors, including cardiac deaths, inaccurate planning, and the prolongation of treatment time in the 74 Gy group (7). Prolonging the total duration 
of RT, even during RT-CHT, may be detrimental because of the accelerative effect it has on tumor repopulation (8). Treatment acceleration may overcome the effects of prolonged treatment time associated with reduced treatment intensity. Such acceleration can be obtained via hyperfractionation (i.e., treatment with a fractional dose below 1.8 Gy given in more than 1 fraction per day), or by hypofractionation (i.e., treatment given with fractional doses higher than $2.2 \mathrm{~Gy} /$ fraction). There is evidence to suggest that a very high dose per fraction given using stereotactic techniques, so-called stereotactic body radiation therapy (SBRT), improves the treatment outcome in the early stages of peripherally located NSCLC (9). However, the administration of high doses per fraction may be harmful in the management of central tumors, resulting in a damage to late-responding tissues of great vessels, bronchi, heart, and esophagus. The issues of modified fractionation and total dose escalation will be discussed in the current review.

\section{Radiobiological background}

The tumor tissue response to fractionated RT, administered in daily fractions of $\sim 2 \mathrm{~Gy}$, can be explained by the $5 \mathrm{Rs}$ of radiobiology: reoxygenation of hypoxic tumor cells, repair of sublethal cellular damage, redistribution of cells within the cell cycle, repopulation of cells after irradiation, and the intrinsic radiosensitivity of the tumor clonogens $(10,11)$. These five factors can work in opposite directions, depending on the tumor characteristics and the manner in which the RT is delivered. When tumors are treated with conventional fractionated radiation with a small dose per fraction, proportions of hypoxic (and consequently, radioresistant) cells are reoxygenated during the interval between fractions and regain radiosensitivity; this is the major benefit of multifractionated RT. Another benefit is that it facilitates the increase in overall cell kill by redistribution of the resistant survivors that were left behind after the selective killing of the most radiosensitive tumor cells in the cell cycle into more radiosensitive phases, prior to the administration of subsequent doses. On the other hand, when tumors are treated with conventional fractionated irradiation, the number of tumor cells that must be sterilized increases, as repair and repopulation produce increased cell survival: by allowing for the repair of sub-lethal damage in irradiated cells after individual radiation doses and by allowing proliferation to occur between radiation doses. However, the same two processes that result in a lower tumor cell kill rate carry the major advantage of restoring normal tissues. Intrinsic cellular radiosensitivity accounts for the different levels of tolerance of tissues to fractionated irradiation.

\section{Modified fractionation}

Altered fractionation schedules used in clinical practice are based on the manipulation of the aforementioned processes so as to maximize tumor cell kill while avoiding toxicity in normal tissue, particularly in late-responding tissues. The goal of hyperfractionation (i.e., using a reduced dose per fraction over a conventional overall treatment time with multiple fractions per day), is to increase the therapeutic differential between the tumor and late-responding normal tissues, as owing to a greater capacity for sublethal injury repair, late-responding tissues are spared by reducing the dose per fraction, while the dose per fraction has only a small effect on tumor control (12). During a course of RT, the proliferation of the surviving cells could lead to repopulation of the tumor and, consequently, to local failure (13); however, the reduced overall treatment time achieved by the use of accelerated schedules of RT may overcome this adverse outcome in tumors which exhibit rapid proliferation, including NSCLC (14). Accelerated hyperfractionated regimens were designed to combine both a shortening of the overall treatment time and a reduction in dose per fraction in an effort to gain a therapeutic benefit (i.e., limiting the repopulation of tumor clonogens while sparing late normal tissue morbidity). However, in both accelerated RT and in hyperfractionation, the dose per week is increased compared with conventional fractionation. Together with a shorter overall treatment time, this is expected to produce an increase in early normal tissue damage.

If the possible morbidity of the irradiated normal tissues is considered, hypofractionation (i.e., the use of doses per fraction higher than 2 Gy) seems to have no radiobiological benefit compared with standard fractionation, because of the increased dose per fraction for late-responding tissues and shortened overall treatment time for earlyresponding tissues. To reduce the risk of damage to lateresponding normal tissues, a decrease in total dose is needed, which could potentially lead to a reduction in tumor control probability. However, the shorter overall treatment time may compensate for this negative effect, and hypofractionation may be used as a convenient way of accelerating treatment. Moreover, advances in image guidance and improved treatment planning can offer more precise delivery of large doses to tumors with reduced 
margins and high gradients outside the target, thereby minimizing doses to relatively large volumes of surrounding normal tissues. Thus, moderate hypofractionation with doses per fraction within the range of 2.25 to $3.5 \mathrm{~Gy}$ is routinely and successfully used for curative radiation therapy for NSCLC in many centers worldwide (15-17).

\section{SBRT}

While fractionation represents a method for improving the therapeutic ratio between the effects of radiation on tumor cells and on normal tissues, as demonstrated via the linear-quadratic (LQ) model of cell killing, it is difficult to comprehend why single-dose radiation therapy should even be considered. The current success of the hypofractionated SBRT regimens for NSCLC RT shows that, clinically, the LQ model underestimates tumor control observed at radiosurgical doses and that large doses per fraction produce greater antitumor efficacy than those predicted by classic radiobiology, or the 5 Rs. This has raised the question as to whether classic radiobiological modeling, and the LQ model, are appropriate for large doses per fraction. For such large doses, within the range of 10-20 Gy, tumor response may result from mechanisms other than tumor cell killing, for which the LQ model might not apply (18-20). Several studies have suggested that there might be other tumoricidal effects, different from the mechanisms of tumor killing of conventionally fractionated RT, such as enhancement of systemic antitumor immunity (21), acid sphingomyelinase-dependent rapid endothelial apoptosis followed by death of cells that appeared to be intact (22), or indirect/necrotic tumor cell death due to vascular (23) or other stromal damage. Any of these nonstandard "new biology" effects (24), could make SBRT more effective than would be expected based on clinical experience with fractionated irradiation. Nonetheless, such effects should be considered theoretical, while the higher tumor control probabilities (TCPs) achieved with SBRT for NSCLC can be explained by the much higher biological effective doses (BEDs) delivered to the tumors $(25,26)$, which is entirely consistent with the predictions of the LQ model $(25,27)$. Although several alternative "high dose" models have been developed to describe a deviation from the typical LQ shape of the cell survival curve that is observed beyond a certain threshold dose- - such as the universal survival curve (USC) model (18), the generalized LQ model (19), and the linearquadratic-linear (LQ-L) model (20)-there is insufficient clinical evidence that the LQ needs to be modified or replaced at high doses $(25,27,28)$. The published clinical local control data is consistent with this model being reasonably predictive of in vitro and in vivo normal tissue dose-response relations in the dose per fraction range from small (<2 Gy) to very large (18-20 Gy) fraction sizes $(25,29)$. However, both preclinical data and modeling studies show that tumor hypoxia is more of a detrimental factor for single-dose treatments than for fractionated irradiation; this was confirmed for NSCLC, in which SBRT-like 3to 5 -fractions hypofractionated schedules were suggested to be optimal for hypoxic tumors, despite the increased risk of intra-fraction repair due to a synergistic effect with inter-fraction reoxygenation (30). For the same BED, tumor control was significantly lower with single doses than with fractionated irradiation, consistently with the predicted loss of tumor response attributed to the tumor hypoxia (25). Therefore, the high cure rates of NSCLC achieved with SBRT result mainly from the fact that this technique provides dose distribution that makes it possible to prescribe BEDs of 100 Gy or more. For early-stage NSCLC patients undergoing 3D-CRT and SBRT, local control data shows that regardless of fractionation, higher TCPs are obtained by delivering higher tumor BEDs (26). Notably, it has been demonstrated that highly conformal dose delivery combined with quasi-parallel normal tissue behavior enables "safe" SBRT for NSCLC (29). When the tumor volume is considerably small, resulting in a reduced volume of uninvolved lung covered by the treatment fields, large fractions can be safely delivered, as, due to relatively small target volumes, there is a "win-win" combination of critical normal tissue sparing and the "parallel" behavior of the principal complication, radiation pneumonitis (29).

\section{Clinical data}

\section{Hyperfractionation}

In two randomized trials on NSCLC that compared hyperfractionation with conventional fractionation using the identical total dose over the same overall treatment time, no survival advantage was observed $(31,32)$. One of these trials included only 110 stage III NSCLC patients and compared $60 \mathrm{~Gy}$ in 30 fractions with hyperfractionated RT $60 \mathrm{~Gy}$ in 40 fractions of 1.5 Gy twice daily (b.i.d.) with a 2-week break after the initial 30 Gy. Despite no statistically significant difference in survival existing in the entire cohort, the authors suggested that such a difference was likely to be demonstrated with larger groups (31). However, 
this was not confirmed in a very similar but sufficiently powered study on 234 patients that compared 60 Gy in 30 fractions with 60 Gy in 40 fractions b.i.d. with a 2-week break after the initial 30 Gy and concomitant chemotherapy (cisplatin and etoposide) in both arms. Hyperfractionated RT was not determined to be superior to conventional RT in terms of survival, local control, or toxicity (32).

Accelerated hyperfractionated RT by shortening the overall treatment time aims to improve the treatment outcome by reducing tumor cell repopulation during RT. However, the results of respective trials that compared accelerated hyperfractionated RT with conventionally fractionated RT were contradictory. The Intergroup (RTOG 8808) phase III study on 458 patients with unresectable stage II/III NSCLC compared 69.6 Gy in 1.2 Gy per fraction b.i.d. with standard RT of $60 \mathrm{~Gy}$ in 30 fractions alone and the same schedule of standard RT preceded by two cycles of cisplatin + vinblastine. The treatment time of about 6 weeks was similar for standard RT and accelerated hyperfractionated RT; however, by giving two fractions per day, the BED corrected for the overall treatment time was higher in the experimental arm, 61.9 vs. $55.5 \mathrm{~Gy}$, for b.i.d. RT and standard RT, respectively. The overall survival of the patients who received sequential CHT-RT was statistically superior $v s$. the other two arms of the study. The twice-daily RT arm, although better, was not statistically superior in survival than the standard radiation arm. Median overall survival for standard RT alone was 11.4 months; for CHT and standard RT, 13.2 months; and for hyperfractionated RT, 12 months (33). The CHART trial (continuous, hyperfractionated, accelerated RT), which compared a very accelerated RT regimen of 54 Gy in 36 fractions of 1.5 Gy 3 times per day on 12 consecutive days with conventional RT (60 Gy in 30 fractions in 6 weeks), produced opposing results. A total of 563 patients with stage I-III unresectable NSCLC were included. It was demonstrated that CHART provides the benefits of a $22 \%$ reduction in the relative risk of death and a $21 \%$ reduction in the relative risk of local progression $(\mathrm{P}=0.033)$ in comparison with the conventional RT arm. The 2-year overall survival was $29 \%$ and $20 \%$, in the CHART and control arm, respectively ( $\mathrm{P}=0.008)$ (34). However, this survival benefit of RT accelerated by hyperfractionation was not confirmed by other studies. The CHARTWEL trial (CHART weekend less) compared conventional RT (66 Gy in 33 fractions over 6.5 weeks) with 60 Gy in 40 fractions (treatment 3 times a day excluding weekend days over 2.5 weeks). The use of neoadjuvant CHT was left at the discretion of the participating centers. There was no survival benefit with the use of this very accelerated form of RT (35). Unfortunately, the ECOG 2597 trial, in which stage III patients were randomized to conventional RT 64 Gy (2 Gy/fraction) vs. hyperfractionated accelerated RT (HART), 57.6 Gy (1.5 Gy b.i.d. interdigitated with a third daily fraction of 1.8 Gy encompassing only gross disease, for an overall treatment time of 2.5 weeks) after two cycles of neoadjuvant CHT (paclitaxel and carboplatin) was closed prematurely after inclusion of 141 patients. The median survival was 20.3 and 14.9 months for HART and conventional RT, respectively $(\mathrm{P}=0.28)$ (36). Since the advent of evidence regarding the superiority of concomitant RT-CHT over RT alone for stage III NSCLC, the interest in researching hyperfractionated RT has been decreasing. To assess the value of hyperfractionated accelerated RT in NSCLC, an individual patient data meta-analysis of randomized trials comparing modified RT schedules with conventional RT was performed (37). Ten trials involving 2000 NSCLC patients were included. Six of these 10 trials tested hyperfractionated accelerated RT against conventionally fractionated RT (33-36), and 2 trials tested hyperfractionation without dose escalation given over identical overall treatment time as conventional RT (31,32). In addition, a trial with accelerated conventionally fractionated RT (60 Gy in 30 fractions in 3 weeks) vs. conventional RT (60 Gy in 30 fractions in 6 weeks) with or without concurrent carboplatin (38) was included. The meta-analysis concluded that modified fractionation schedules (hyperfractionated accelerated, hyperfractionated without acceleration, and accelerated conventionally fractionated) improved overall survival compared to conventional schedules of RT, resulting in an absolute benefit of $2.5 \%$ at 5 years (hazard ratio: 0.88 , 95\% CI: $0.80-0.98, \mathrm{P}=0.009)$. The use of modified RT schedules increased acute esophageal toxicity, $\mathrm{P}<0.001$ (37). Although no evidence of heterogeneity was found between the trials included in the meta-analysis, the clinical utility of its findings are reduced by the inclusion of very different RT schedules (accelerated and non-accelerated, with and without dose escalation, hyperfractionated and conventionally fractionated). In another meta-analysis based on 21 randomized trials that compared different timecorrected BEDs, it was concluded that the benefit of BED escalation seen in the trials without CHT did not differ significantly between randomized comparisons in which the higher-dose arm was hyperfractionated and those in which it was not (39). This indicates that it is the intensity of 
treatment that influences patient outcomes, rather than the method of fractionation.

\section{Hypofractionation: SBRT}

The use of high doses per fraction in SBRT for inoperable peripherally located early-stage NSCLC became a standard of care. High (ranging from $80 \%$ to $100 \%$ ) local control rates with minimal toxicity made it the treatment of choice even before its superiority over conventionally fractionated RT had been evidenced by controlled trials (40). In a multicenter randomized trial that included 101 patients with peripherally located T1-T2aN0M0 NSCLC, giving 3 fractions of 18 Gy or 4 fractions of 12 Gy provided statistically significant local control benefit over standard RT (66 Gy in 33 daily fractions or 50 Gy in 20 daily fractions) (9). Only one small randomized trial evaluated the issue of dose in SBRT for NSCLC. Ninety-eight patients with inoperable T1-T2NOM0 NSCLC were enrolled and randomly assigned to 1 fraction of 30 vs. 60 Gy in 3 fractions. There were no differences in grade 3 and higher toxicity, local control, and overall survival between arms. Short-term (up to 6 months) quality of life (social functioning and dyspnea) measures favored the single-fraction SBRT arm (41). Due to a lack of evidence from randomized studies, dose-fractionation regimens for SBRT are based on the experience from large prospective studies and are selected at the discretion of the treating physicians, who utilize a risk-adapted approach with regard to the tumor size, location, and proximity to critical structures. ESTRO-ACROP experts recommend the use of fractionation regimen $3 \times 15$ Gy for peripherally located lesions and $4 \times 12$ Gy for cases with broad chest wall contact. Minimum doses should range between 105 and 113 Gy BED10. Such a fractionation assures the BED10 will be above $100 \mathrm{~Gy}$, which is necessary for achieving $>90 \%$ tumor control probability (41). BED10 >140 Gy may be associated with further increase in the local control but at the expense of mildly increased toxicity with no difference in survival $(42,43)$.

The dose/fractionation issue in SBRT for centrally located tumors is pertinent. In tumors located within a $2 \mathrm{~cm}$ radius of large airways a significant risk of major damage was observed with the use of 60-66 Gy in 3 fractions. Grade 3-5 toxicity occurred in 5 of 48 patients with peripheral tumors $(10.4 \%)$ and in 6 of 22 patients $(27.3 \%)$ with central tumors $(\mathrm{P}=0.088)(44,45)$. The ASTRO guidelines recommend avoiding a 3 -fraction regimen in this setting and to use 4-5 lower fractional doses instead. In cases in which the use of hypofractionated RT is deemed to carry too high risk, the use of $6-15$ fractions should be considered (46). The risk of complications in SBRT for central tumors is related to the decreased tolerance (discussed above) of late-responding tissues such as the bronchi, esophagus, and great vessels to high fractional doses, which increases the occurrence of major damage in the form of fistulas or fatal hemoptysis. A body of evidence has been gathered on the safety of SBRT for the treatment of centrally located tumors. In particular, caution should be exercised in cases of so-called ultracentral tumors, for which there is no unanimous definition. In most trials, a tumor is considered ultracentral if the planning target volume touches the proximal bronchial tree (PBT), great vessels, or esophagus. Some reports have demonstrated an increase in major toxicity (including fistulas and fatal hemoptysis) in SBRT for tumors largely abutting the PBT (47-50), whereas others have not (51-53). The recently completed NRG Oncology/RTOG 0813 phase I/II prospective trial involved 100 eligible patients with central T1-2N0M0 tumors that were accrued into a dose-escalating 5-fraction SBRT schedule ranging from 10 to $12 \mathrm{~Gy} /$ fraction. Dose-limiting toxicity, defined as any treatment-related grade 3 or higher toxicity occurring within the first year after treatment, was observed in $7.2 \%$ of patients at the $12 \mathrm{~Gy} /$ fraction level, with a 2-year local control of $88 \%$. However, despite only very few patients in this trial having ultracentral tumors, five cases of toxic deaths occurred beyond the first year ( 3 fatal hemoptysis, 1 esophageal ulcer with possible fistula into major vessels, and 1 unspecified) (54). While some results have indicated that SBRT may be safe for ultracentral tumors, caution should be applied in selecting and treating these patients until large prospective trials have been completed. Strict adherence to the dose constraints based on the experience from prospective trials, a homogeneous dose distribution in the planning target volume within organs at risk, and limitation of both normal organ maximum point doses and volumes receiving high doses is needed (55). Meanwhile, ESTRO-ACROP experts recommend using a schedule of $8 \times 7.5$ Gy for SBRT of central tumors (42). However, the evidence on which this is based is still thin. The safety and efficacy of $8 \times 7.5$ Gy schedule was demonstrated in a retrospective study, in which this regimen was used to treat 63 patients with central tumors. There was no grade 4/5 toxicity reported in this group. Local control at 3 years was about $90 \%$ and was no different to that of 445 patients with peripherally located tumors who received a regimen of fewer-fractions within the same timeframe. However, 
9 cardiac and unknown causes of death in a group of 63 patients elicits caution about the true extent of the risk of major toxicity that may accompany this schedule (56). Results on the safety of this approach from prospective trials, such as the EORTC Lungtech trial $(57,58)$ and the Canadian Sunset trial (59) are eagerly awaited.

\section{Hypofractionation: moderate bypofractionation with or without CHT}

Increase in treatment intensity by hypofractionation, which in relation to radical intent RT in NSCLC refers to the use of fractions between 2.25 Gy and 5 Gy, is often called a moderate hypofractionation, in contrast with the use of very large sizes of fractions in SBRT. The rationale for using hypofractionation is based on the notion that shortening the treatment time is beneficial in RT for NSCLC (8), as well as on its convenience for patients and lower cost, and also on the conviction that new technologies are able to achieve a significant dose-per-fraction escalation without unacceptable lung and esophageal morbidity (60). In the systematic review of radical hypofractionated RT with fractional doses between 2.3 and 3.5 Gy for locally advanced NSCLC, a total of 33 trials were included; in 15 trials, RT was combined with concurrent CHT. In both concurrent and non-concurrent RT-CHT schedules, an improvement in overall survival was associated with higher BED. Notably, the reported toxicity rate was low: late pulmonary and esophageal toxicity ranged from $1.2 \%$ to $12.2 \%$, and the greatest incidence of acute esophageal toxicity was $14.9 \%$, which appears to be better than in conventional concurrent RT-CHT (61). However, such an approach has not been validated in phase III trials. Despite the low toxicity rates reported in most trials, doubt surrounding the real extent of this toxicity persists. There is a lack of established dose constraints and patterns of the toxicity in hypofractionation for lung cancer. In accelerated hypofractionated schedules, there are additional organs at risk not contoured in conventional fractionation, such as the bronchi and brachial plexus. There are also other types of toxicities not reported in most reports on conventional RT, such as fistulas, hemoptysis, and strictures. Attempts to quantify a risk of complications for moderately hypofractionated RT are hampered by the lack of large prospective trials using such an approach, and by the considerable heterogeneity of reporting toxicity across the published studies on hypofractionation in NSCLC. Some reports contain only toxicity by group (e.g., only > grade 2), some do not distinguish between early and late toxicity, while most consider a short follow-up for toxicity occurrence and do not take into account specific toxicity of late-responding tissues (stricture, fistula, hemorrhage) (62). To illustrate this, the reported outcomes are summarized in Table 1, with a focus on toxicity in the published prospective studies on moderate hypofractionation without the use of concurrent CHT (63-72).

Concurrent RT-CHT is the current standard for inoperable stage III NSCLC. Thus, a question arises about the safety and efficacy of combining accelerated hypofractionated RT with CHT. A concern about the increased toxicity of more intense treatment schedules seems justified. Published data has produced conflicting results. Moderately hypofractionated schedules with lowdose daily cisplatin achieved excellent outcomes in the centers with a long experience of using them. A schedule of 66 Gy in daily fractions of 2.75 Gy with daily doses of $6 \mathrm{mg} / \mathrm{m}^{2}$ cisplatin was validated in two consecutive EORTC trials as promising $(64,73)$. Recently, the results of the phase II trial based on this schema with random allocation to addition or not of weekly cetuximab were published by the same investigators. In a total of 102 stage III patients, the median overall survival was 31.5 months, with a remarkably high 5 -year survival rate of $37.3 \%$. Toxicity was reported as acceptable; however, detailed data on long-term toxicity were not provided (17). Nevertheless, this study's excellent overall outcome shows that such a fractionation schedule with low radiosensitizing doses of CHT given in highvolume centers is promising and should be promulgated.

The results of several small studies indicate the safety of the concurrent delivery of accelerated hypofractionated RT with full-dose CHT (74-77). However, there are also conflicting results. A Chinese phase II study was prematurely terminated after inclusion of 12 patients to the accelerated hypofractionated RT (69 Gy/23 fractions) combined with concurrent platinum-based doublet CHT. The incidence of grade 3 esophagitis was $83 \%$. Grade 3 pneumonitis occurred in 2 of 7 patients who completed the planned RT schedule (78). A phase I/II trial on dose-perfraction escalation (from 2.0 to $2.48 \mathrm{~Gy}$ ) to the total dose of 67.2 Gy with concurrent docetaxel and cisplatin was stopped at the dose per fraction of $2.24 \mathrm{~Gy}$, because of an unacceptable rate of late pulmonary toxicity at a dose-perfraction level of 2.36 Gy (79). In the CALGB 31102 phase I study, which evaluated the feasibility of dose per fraction escalation with accelerated hypofractionated RT with concurrent carboplatin and paclitaxel, the 3 cases of grade 
Table 1 Outcomes with a focus on toxicity from published prospective studies on moderate hypofractionation without the use of concurrent CHT for NSCLC

\begin{tabular}{|c|c|c|c|c|}
\hline $\begin{array}{l}\text { First author } \\
\text { (reference), } \\
\text { No. of patients }\end{array}$ & RT schedule & $\begin{array}{l}\text { Overall } \\
\text { survival } \\
\text { outcome }\end{array}$ & Acute toxicity & Late toxicity \\
\hline $\begin{array}{l}\text { Belderbos (64), } \\
78 \text { stage I-III (in } \\
\text { the arm without } \\
\text { concurrent CHT) }\end{array}$ & $\begin{array}{l}66 \text { Gy in } 24 \text { fractions } \\
(2.75 \text { Gy/fraction, } 5 \text { times a } \\
\text { week) after induction } \mathrm{CHT}\end{array}$ & $\begin{array}{l}\text { Two-year: } \\
34 \%\end{array}$ & $\begin{array}{l}5 \% \text { of grade } 3 \text { esophagitis, } \\
\text { no grade } 5 \text { toxicity }\end{array}$ & $\begin{array}{l}4 \% \text { grade } 3 \text { esophagitis; } 14 \% \text { grade } 3 / 4 \\
\text { pneumonitis; two cases of grade } 4 \text { cardiac } \\
\text { toxicity and one fatal hemoptysis }\end{array}$ \\
\hline $\begin{array}{l}\text { Kepka (65), } 173 \\
\text { stage III }\end{array}$ & $\begin{array}{l}56.7 \text { Gy to } 60.9 \text { Gy in } 21 \\
\text { fractions in } 4 \text { weeks (dose per } \\
\text { fraction escalation from } 2.7 \\
\text { through } 2.8 \text { up to } 2.9 \text { Gy) }\end{array}$ & $\begin{array}{l}\text { Two-year: } \\
32 \%\end{array}$ & $\begin{array}{l}7 \% \text { of grade } 3 \text { esophagitis, } \\
\text { three grade } 5 \text { pneumonitis } \\
\text { (two in the } 60.9 \text { Gy dose } \\
\text { level; and one in patient who } \\
\text { received } 54 \text { Gy in } 20 \text { fractions } \\
\text { because of interstitial lung } \\
\text { disease) }\end{array}$ & $\begin{array}{l}6 \% \text { grade } 3 \text { pneumonitis; one paraparesis } \\
\text { six years after treatment in patients with } \\
\text { maximum dose of } 44 \text { Gy in } 21 \text { fractions, } \\
\text { however, MR revealed a vascular radiation } \\
\text { damage at the level of irradiated spine; } \\
\text { one case of grade } 3 \text { pericarditis }\end{array}$ \\
\hline $\begin{array}{l}\text { Cannon (66), } \\
75 \text { stage I-IV } \\
\text { evaluable }\end{array}$ & $\begin{array}{l}57 \text { to } 85.5 \text { Gy in } 25 \text { fractions } \\
\text { over } 5 \text { weeks }\end{array}$ & $\begin{array}{l}\text { Three-year: } \\
29 \%\end{array}$ & $\begin{array}{l}\text { No grade } 3 \text { acute esophagitis, } \\
\text { pneumonitis }\end{array}$ & $\begin{array}{l}\text { Six cases of grade } 4 / 5 \text { toxicities ( } 3 \text { fatal } \\
\text { hemoptysis, one tracheoesophageal fistula, } \\
\text { one pneumonitis, and one lung abscess) }\end{array}$ \\
\hline $\begin{array}{l}\text { Zhu (67), } 34 \\
\text { stage III }\end{array}$ & $\begin{array}{l}65 \text { Gy in } 20 \text { fractions of } 2.5 \text { Gy } \\
\text { followed by } 5 \text { fractions of } 3 \text { Gy } \\
\text { or } 68 \text { Gy in } 20 \text { fractions of } \\
2.5 \text { Gy followed by } 6 \text { fractions } \\
\text { of } 3 \text { Gy over } 5 \text { weeks }\end{array}$ & $\begin{array}{l}\text { Three-year: } \\
32 \%\end{array}$ & $\begin{array}{l}6 \% \text { of grade } 3 \text { esophagitis; } \\
3 \% \text { of grade } 3 \text { pneumonitis }\end{array}$ & $\begin{array}{l}6 \% \text { ( } 2 \text { cases) of grade } 2 \text { esophageal } \\
\text { stenosis }\end{array}$ \\
\hline $\begin{array}{l}\text { Agolli (68), } 60 \\
\text { stage III/IV }\end{array}$ & $\begin{array}{l}60 \text { Gy in } 20 \text { fractions of } 3 \text { Gy } \\
\text { over } 4 \text { weeks }\end{array}$ & $\begin{array}{l}\text { Two-year: } \\
40 \%\end{array}$ & $\begin{array}{l}5 \% \text { of grade } 3 \text { esophagitis; } \\
6 \% \text { of grade } 3 \text { pneumonitis }\end{array}$ & $\begin{array}{l}2 \% \text { of grade } 3 \text { esophagitis; } 3 \% \text { of grade } 3 \\
\text { pneumonitis }\end{array}$ \\
\hline $\begin{array}{l}\text { Bral }(71), 40 \\
\text { stage III }\end{array}$ & $\begin{array}{l}70.5 \text { Gy in } 30 \text { fractions of } 2.35 \\
\text { Gy over } 6 \text { weeks }\end{array}$ & $\begin{array}{l}\text { Median: } \\
17 \text { months }\end{array}$ & $\begin{array}{l}3(7.5 \%) \text { grade } 3 \text { pneumonitis } \\
+2(5 \%) \text { grade } 5 \text { pneumonitis }\end{array}$ & $16 \%$ grade 3 pneumonitis \\
\hline
\end{tabular}

CHT, chemotherapy; NSCLC, non-small cell lung cancer.

5 respiratory toxicities, including 2 fatal hemoptysis led to the premature termination of the study after inclusion of 22 patients. The authors demonstrated that $60 \mathrm{~Gy}$ in 24 fractions (2.5 Gy/fraction) is probably the maximum tolerable dose that may be tested in future clinical trials (80). The safety of hypofractionated RT concurrent with fulldose CHT may be confirmed only by a randomized trial that would compare such an approach with conventional fractionation. Currently, no such trial exists. Indirectly, we may estimate the safety of such an approach based on a trial that compared accelerated hypofractionated RT (55 Gy in 20 fractions) with 3-4 cycles of cisplatin and vinorelbine given either sequentially or concurrently. Among the 130 included patients, there was no difference in the grade $3-5$ toxicity, $31 \%$ and $36 \%$, respectively, in the concurrent and sequential arms, $\mathrm{P}=0.57$. However, when grade 4 and 5 toxicities were analyzed separately, $9 \%$ and $6 \%$ of grade 4 and 5 toxic events were observed 
in the concurrent arm $v s$. none in the sequential arm (81). In a recently completed NCT02367443 trial, in which two cycles of $80 \mathrm{mg} / \mathrm{m}^{2}$ cisplatin and $40 \mathrm{mg} / \mathrm{m}^{2}$ vinorelbin were given concurrently with $58.8 \mathrm{~Gy}$ in 21 fractions for 4 weeks, despite an encouraging median overall survival of 38 months, 7 toxic deaths were reported, including 3 cases of fatal hemoptysis (82). Estimating the risk of fatal hemoptysis caused by hypofractionation is difficult because of the differences in patient selection and treatment schemes. Prospective studies on hypofractionation usually report the rate of fatal hemoptysis, as it is commonly believed that a large dose per fraction may damage the bronchial wall, whereas in the series on conventionally fractionated RT, such events are probably underreported. However, some tumor characteristics, such as central location, squamous histology, and tumor cavitation, increase the risk of fatal hemoptysis independently of the RT fractionation (83). In a prospective study that randomized patients with central tumors to external beam RT 60 Gy in 30 fractions vs. the same external beam RT plus brachytherapy boost, there were 6 $(14 \%)$ deaths caused by hemoptysis in 42 patients in the arm without brachytherapy (84).

Final confirmation of the value of concurrent accelerated hypofractionated RT-CHT should come from a prospective trial with randomized comparison of this approach and conventional RT-CHT. Encouraging data on the survival and convenience of the hypofractionated approach justify the continuation of this research. However, for reliable comparison, more data relating to the toxicity attributable to the damage to the central and perihilar structures and correlated with the dose to the PBT in the conventional approach should certainly be collected. Reporting toxicity for these structures requires an appropriate length of followup of at least a few years. In a study that prospectively included 79 patients for hypofractionated RT with dose per fraction escalation from 57 to 85.5 Gy in 25 fractions using helical tomotherapy, the preliminary results with a median follow-up of 8 months claimed that this schedule was safe with no grade 3 toxicity (85). With an update of this study published 5 years later, it appeared that late grade 4 and 5 toxicities occurred in 6 patients and were attributable to the damage to the central and perihilar structures and correlated with the dose to the PBT (66).

\section{Total dose in RT and RT-CHT}

The current standard dose in radical RT for NSCLC is 60-66 Gy in 30-33 fractions, which was established in an old RTOG trial in 551 patients compared four different RT regimens: 40 Gy split course $(5 \times 4$ Gy in 1 week, 2 weeks' rest and an additional $5 \times 4$ Gy in 1 week) or 40, 50, or 60 Gy in 2 Gy per fraction (without dose inhomogeneity correction) 5 times a week. Patients treated in the highest dose (60 Gy) arm achieved the highest local control and this schema has since become the standard dose to date in patients treated with and without CHT (86). Technological progress with the development of threedimensional conformal RT offered the opportunity to deliver higher tumor doses with acceptable complication rates compared to earlier RT techniques, because of the reduction in the volume of normal tissue irradiated. Phase I/II studies on the RT dose escalation up to the range of 80-100 Gy were encouraging, showing the feasibility of such an approach (87-90). A prerequisite for RT with dose escalation was the use of advanced technologies and the possibility for omission of elective nodal irradiation due to the development of better mediastinal imaging in order to obtain the maximal limitation of the irradiated healthy tissues (91). With evidence that concurrent RT-CHT improves survival in locally advanced NSCLC, confirmation that a higher dose also improves treatment outcomes also in the concurrent RT-CHT approach has become pertinent. An unexpected outcome came from the RTOG-0617 phase III trial, which investigated the issue of dose escalation from $60 \mathrm{~Gy} / 30$ fractions (control arm) to $74 \mathrm{~Gy} / 37$ fractions (experimental arm) with concurrent paclitaxel and carboplatin with or without cetuximab in both arms. Patients who received 74 Gy/37 fractions had a median overall survival of 20.3 months, compared with 28.7 months in patients who received the standard dose of $60 \mathrm{~Gy} / 30$ fractions $(\mathrm{P}=0.004)$ (6). The prolongation of treatment in the higher dose arm is considered to be one of the reasons for the inferior overall survival $(7,8)$. With growing evidence that the prolongation of treatment time with increasing radiation dose may compromise any beneficial effect of a higher dose, the subsequent dose-escalation trials were designed with the restriction of keeping the overall time to 5-6 weeks via partial hyperfractionation, acceleration without the change of size of fractional dose (giving an extra dose of 2 Gy per week), or moderate hypofractionation. Additionally, a strategy of individualized accelerated isotoxic dose RT (INDAR) escalation was developed. In isotoxic RT planning, the prescribed dose is increased incrementally until an organ-at-risk maximum tolerated dose is reached. In sequential CHT and RT and 
in $\mathrm{RT}$ alone, these results were promising (the median dose escalation was up to 64.8 Gy delivered in $25 \pm 5.8$ days, with partial hyperfractionation), with median overall survival of 21 months and minimal toxicity (92). However, the early results of INDAR in concurrent RT-CHT seemed to be similar to those for standard fractionation and dose RT (93). The mature results of the prospective INDAR trial with concurrent full-dose platinum-based CHT were recently published. RT was given using IMRT to a dose of $45 \mathrm{~Gy}$ in 30 fractions b.i.d., followed by $2 \mathrm{~Gy} /$ fraction daily until a total dose determined by the normal tissue constraints was reached. The mean dose escalation was mild, up to 66 Gy delivered over 38 days. The median overall survival was 20 months, which is no better than that of standarddose concurrent RT-CHT (94). A Swedish randomized trial that compared a standard dose of 68 Gy with concurrent cisplatin and vinorelbin with the same CHT combined concurrently with dose escalation up to 84 Gy (by giving an extra 2 Gy per week to a total number of 6 fraction/ week) was terminated after the inclusion of 36 patients due to excessive toxicity ( 5 toxic deaths in the experimental arm and 2 in the standard arm) and worsening of survival in the dose-escalation arm (95). In another prospective trial on 120 patients, an isotoxic dose escalation with concurrent full-dose cisplatin and vinorelbin was evaluated. The dose was escalated up to 63-73 Gy over 40 days in the 6-week schedule (5 fractions per week), and up to 63-71 Gy over 33 days in the 5 -week schedule (6 fractions per week including 2 on the same day). Overall survival was longer in the 6-week schedule than the 5-week schedule (median: 41.2 vs. 22.1 months, $\mathrm{P}=0.04)$. The authors concluded that this outcome should stimulate further research on individualized dose prescription in a concurrent RT-CHT setting. Interestingly, dose intensification with treatment acceleration for 5 weeks seemed to carry no benefit (96).

The abovementioned results warn that dose escalation and/or dose intensification in a concurrent RT-CHT setting should be considered with caution. This is in line with a more recent meta-analysis that investigated RT doseresponse relationships in NSCLC and reported survival benefits for dose escalation with RT alone and no survival benefit in the concurrent RT-CHT setting (39). From the trials, we learned that dose escalation in a linear fashion does not improve outcomes for all patients, and thus there is a need to tailor the prescription to the individual patient. Personalized dose prescription is an interesting strategy that has the goal of adapting the dose prescription to the individual patient to achieve a safe dose escalation and also, in some cases, de-escalation. There are numerous strategies for achieving this; however, these are mostly the subject of preclinical studies, and more evidence is needed before they are introduced to clinical practice $(97,98)$. So far, evidence from the PACIFIC trial shows that standard-dose RT (>54 Gy) given concurrently with full-dose CHT followed by immunotherapy with durvalumab is superior to the same RT-CHT without immunotherapy (99). Optimization of concurrent RT-CHT combined with immunotherapy, including total dose, is the subject of ongoing and planned clinical trials. In routine practice, there is no evidence for RT dose escalation in combined RT-CHT followed by administration of an immune agent.

\section{Conclusions}

Concurrent RT-CHT combined with immunotherapy is a standard of care in locally advanced NSCLC. We have no evidence that dose escalation and/or intensification bears any relevance to the improvement of outcome in such an approach. However, with the use of modern RT techniques in sequential CHT and RT and in RT alone, a dose escalation with the restriction that the overall time should not be prolonged beyond 5-6 weeks seems promising. The use of high fractional doses in SBRT of peripheral inoperable lung cancer is the standard of care. The treatment of central lesions with SBRT provides a challenge because of the increased risk of injury to the bronchi and mediastinal critical structures.

\section{Acknowledgments}

Funding: None.

\section{Footnote}

Provenance and Peer Review: This article was commissioned by the Guest Editors (Jacek Jassem, Rafal Dziadziuszko) for the focused issue "Radiotherapy in thoracic malignancies" published in Translational Lung Cancer Research. The article was sent for external peer review organized by the Guest Editors and the editorial office.

Peer Review File: Available at http://dx.doi.org/10.21037/ tlcr-20-253

Conflicts of Interest: Both authors have completed the ICMJE uniform disclosure form (available at http:// 
dx.doi.org/10.21037/tlcr-20-253). The focused issue "Radiotherapy in thoracic malignancies" was commissioned by the editorial office without any funding or sponsorship. The authors have no other conflicts of interest to declare.

Ethical Statement: The authors are accountable for all aspects of the work in ensuring that questions related to the accuracy or integrity of any part of the work are appropriately investigated and resolved.

Open Access Statement: This is an Open Access article distributed in accordance with the Creative Commons Attribution-NonCommercial-NoDerivs 4.0 International License (CC BY-NC-ND 4.0), which permits the noncommercial replication and distribution of the article with the strict proviso that no changes or edits are made and the original work is properly cited (including links to both the formal publication through the relevant DOI and the license). See: https://creativecommons.org/licenses/by-nc-nd/4.0/.

\section{References}

1. Malvezzi M, Carioli G, Bertuccio P, et al. European cancer mortality predictions for the year 2017, with focus on lung cancer. Ann Oncol 2017;28:1117-23.

2. Delaney G, Barton M, Jacob S, Jalaludin B. A model for decision making for the use of radiotherapy in lung cancer. Lancet Oncol 2003;4:120-8.

3. Available online: https://seer.cancer.gov/statfacts/html/ lungb.html, accessed 28.12.2019.

4. Aupérin A, Le Péchoux C, Rolland E, et al. Meta-analysis of concomitant versus sequential radiochemotherapy in locally advanced non-small-cell lung cancer. J Clin Oncol 2010;28:2181-90.

5. Aupérin A, Le Péchoux C, Pignon JP, et al. Concomitant radio-chemotherapy based on platin compounds in patients with locally advanced non-small cell lung cancer (NSCLC): a meta-analysis of individual data from 1764 patients. Ann Oncol 2006;17:473-83.

6. Bradley JD, Paulus R, Komaki R, et al. Standard-dose versus high-dose conformal radiotherapy with concurrent and consolidation carboplatin plus paclitaxel with or without cetuximab for patients with stage IIIA or IIIB non-small-cell lung cancer (RTOG 0617): a randomised, two-by-two factorial phase 3 study. Lancet Oncol 2015;16:187-99.

7. Faivre-Finn C. Dose escalation in lung cancer; have we gone full circle?. Lancet Oncol 2015;16:125-7.
8. Machtay M, Bae K, Movsas B, et al. Higher biologically effective dose of radiotherapy is associated with improved outcomes for locally advanced non-small cell lung carcinoma treated with chemoradiation: an analysis of the Radiation Therapy Oncology Group. Int J Radiat Oncol Biol Phys 2012;82:425-34.

9. Ball D, Mai GT, Vinod S, et al. Stereotactic ablative radiotherapy versus standard radiotherapy in stage I nonsmall-cell lung cancer (TROG 09.02 CHISEL): a phase 3 , open-label, randomized controlled trial. Lancet Oncol 2019;20:494-503.

10. Withers HR. The four Rs of radiotherapy. Adv Radiat Biol 1975;5:241-71.

11. Steel GG, McMillan TJ, Peacock JH. The 5Rs of radiobiology. Int J Radiat Biol 1989;56:1045-8.

12. Withers HR. Biologic basis for altered fractionation schemes. Cancer 1985;55:2086-95.

13. Withers HR, Taylor JM, Maciejewski B. The hazard of accelerated tumor clonogen repopulation during radiotherapy. Acta Oncol 1988;27:131-46.

14. Fowler JF, Chappell R. Non-small cell lung tumors repopulate rapidly during radiation therapy. Int $\mathrm{J}$ Radiat Oncol Biol Phys 2000;46:516-7.

15. Din OS, Harden SV, Hudson E, et al. Accelerated hypo-fractionated radiotherapy for non-small cell lung cancer: results from 4 UK centres. Radiother Oncol 2013;109:8-12.

16. Robinson SD, Tahir BA, Absalom K, et al. Radical accelerated radiotherapy for non-small cell lung cancer (NSCLC): a 5-year retrospective review of two dose fractionation schedules. Radiother Oncol 2020;143:37-43.

17. Walraven I, van den Heuvel M, van Diessen J, et al. Longterm follow-up of patients with locally advanced non-small cell lung cancer receiving concurrent hypofractionated chemoradiotherapy with or without cetuximab. Radiother Oncol 2016;118:442-6.

18. Park C, Papiez L, Chichuan Z, et al. Universal survival curve and single fraction equivalent dose: useful tools in understanding potency of ablative radiotherapy. Int J Radiat Oncol Biol Phys 2008;70:847-52.

19. Wang JZ, Huang Z, Lo SS, et al. A generalized linearquadratic model for radiosurgery, stereotactic body radiation therapy, and high-dose rate brachytherapy. Sci Transl Med 2010;2:39ra48.

20. Astrahan M. Some implications of linear-quadratic-linear radiation dose response with regard to hypofractionation. Med Phys 2008;35:4161-72.

21. Lee Y, Auh SL, Wang Y, et al. Therapeutic effects of 
ablative radiation on local tumor require CD8 $+\mathrm{T}$ cells: Changing strategies for cancer treatment. Blood 2009;114:589-95.

22. Fuks Z, Kolesnick R. Engaging the vascular component of the tumor response. Cancer Cell 2005;8:89-91.

23. Park HJ, Griffin RJ, Hui S, et al. Radiation-induced vascular damage in tumors: implications of vascular damage in ablative hypofractionated radiotherapy (SBRT and SRS). Radiat Res 2012;177:311-27.

24. Brown JM, Koong AC. High-dose single-fraction radiotherapy: Exploiting a new biology? Int J Radiat Oncol Biol Phys 2008;71:324-5.

25. Brown JM, Carlson DJ, Brenner DJ. The tumor radiobiology of SRS and SBRT: are more than the 5 Rs involved? Int J Radiat Oncol Biol Phys 2014;88:254-62.

26. Mehta N, King CR, Agazaryan N, et al. Stereotactic body radiation therapy and 3-dimensional conformal radiotherapy for stage I non-small cell lung cancer: A pooled analysis of biological equivalent dose and local control. Pract Radiat Oncol 2012;2:288-95.

27. Brown JM, Brenner DJ, Carlson DJ. Dose escalation, not "new biology," can account for the efficacy of stereotactic body radiation therapy with non-small cell lung cancer. Int J Radiat Oncol Biol Phys 2013;85:1159-60.

28. Klement RJ, Sonke JJ, Allgäuer M, et al. Estimation of the $\alpha / \beta$ ratio of non-small cell lung cancer treated with stereotactic body radiotherapy. Radiother Oncol 2020;142:210-6

29. Nahum AE. The radiobiology of hypofractionation. Clin Oncol (R Coll Radiol) 2015;27:260-9.

30. Lindblom E, Dasu A, Toma-Dasu I. Optimal fractionation in radiotherapy for non-small cell lung cancer - a modelling approach. Acta Oncol 2015;54:1592-8.

31. Bonner JA, McGinnis WL, Stella PJ, et al. The possible advantage of hyperfractionated thoracic radiotherapy in the treatment of locally advanced nonsmall cell lung carcinoma: results of a North Central Cancer Treatment Group Phase III Study. 1998;82:1037-48.

32. Schild SE, Stella PJ, Geyer SM, et al. Phase III trial comparing chemotherapy plus once-daily or twice-daily radiotherapy in Stage III non-small-cell lung cancer. Int J Radiat Oncol Biol Phys 2002;54:370-8.

33. Sause W, Kolesar P, Taylor S IV, et al. Final results of phase III trial in regionally advanced unresectable nonsmall cell lung cancer: Radiation Therapy Oncology Group, Eastern Cooperative Oncology Group, and Southwest Oncology Group. Chest 2000;117:358-64.

34. Saunders M, Dische S, Barrett A, et al. Continuous, hyperfractionated, accelerated radiotherapy (CHART) versus conventional radiotherapy in non-small cell lung cancer: mature data from the randomised multicentre trial. CHART Steering committee. Radiother Oncol 1999;52:137-48.

35. Baumann M, Hermann T, Koch R, et al. Final results of the randomized phase III CHARTWEL-trial (ARO 97-1) comparing hyperfractionated-accelerated versus conventionally fractionated radiotherapy in non-small cell lung cancer (NSCLC). Radiother Oncol 2011;100:76-85.

36. Belani CP, Wang W, Johnson DH, et al. Phase III study of the Eastern Cooperative Oncology Group (ECOG 2597): induction chemotherapy followed by either standard thoracic radiotherapy or hyperfractionated accelerated radiotherapy for patients with unresectable stage IIIA and B non-small-cell lung cancer. J Clin Oncol 2005;23:3760-7.

37. Mauguen A, Le Pechoux C, Saunders MI, et al. Hyperfractionated or accelerated radiotherapy in lung cancer: an individual patient data meta-analysis. J Clin Oncol 2012;30:2788-97.

38. Ball D, Bishop J, Smith J, et al. A randomised phase III study of accelerated or standard fraction radiotherapy with or without concurrent carboplatin in inoperable non-small cell lung cancer: final report of an Australian multi-centre trial. Radiother Oncol 1999;52:129-36.

39. Ramroth J, Cutter DJ, Darby SC, et al. Dose and fractionation in radiation therapy of curative intent for non-small cell lung cancer: meta-analysis of randomized trials. Int J Radiat Oncol Biol Phys 2016;96:736-47.

40. Chi A, Liao Z, Nguyen NP, et al. Systemic review of the patterns of failure following stereotactic body radiation therapy in early-stage non-small-cell lung cancer: clinical implications. Radiother Oncol 2010;94:1-11.

41. Singh AK, Gomez-Suescun JA, Stephans KL, et al. One Versus Three Fractions of Stereotactic Body Radiation Therapy for Peripheral Stage I to II Non-Small Cell Lung Cancer: A Randomized, Multi-Institution, Phase 2 Trial. Int J Radiat Oncol Biol Phys 2019;105:752-9.

42. Guckenberger M, Andratschke N, Dieckmann K, et al. ESTRO ACROP consensus guideline on implementation and practice of stereotactic body radiotherapy for peripherally located early stage non-small cell lung cancer. Radiother Oncol 2017;124:11-7.

43. Stephans KL, Woody NM, Reddy CA, et al. Tumor control and toxicity for common stereotactic body radiation therapy dose-fractionation regimens in stage I non-small cell lung cancer. Int J Radiat Oncol Biol Phys 
2018;100:462-9.

44. Timmerman R, McGarry R, Yiannoutsos C, et al. Excessive toxicity when treating central tumors in a phase II study of stereotactic body radiation therapy for medically inoperable early-stage lung cancer. J Clin Oncol 2006;24:4833-9.

45. Fakiris AJ, McGarry RC, Yiannoutsos CT, et al. Stereotactic body radiation therapy for early-stage non-small-cell lung carcinoma: four-year results of a prospective phase II study. Int J Radiat Oncol Biol Phys 2009;75:677-82.

46. Videtic GMM, Donington J, Giuliani M, et al. Stereotactic body radiation therapy for early-stage non-small cell lung cancer: Executive Summary of an ASTRO Evidence-Based Guideline. Pract Radiat Oncol 2017;7:295-301.

47. Nguyen KNB, Hause DJ, Novak J, et al. Tumor Control and Toxicity after SBRT for Ultracentral, Central, and Paramediastinal Lung Tumors. Pract Radiat Oncol 2019;9:e196-e202.

48. Tekatli H, Haasbeek N, Dahele M, et al. Outcomes of hypofractionated high-dose radiotherapy in poor-risk patients with "ultracentral" non-small cell lung cancer. J Thorac Oncol 2016;11:1081-9.

49. Tekatli H, Duijm M, Oomen-de Hoop E, et al. Normal Tissue Complication Probability Modeling of Pulmonary Toxicity After Stereotactic and Hypofractionated Radiation Therapy for Central Lung Tumors. Int J Radiat Oncol Biol Phys 2018;100:738-47.

50. Haseltine JM, Rimner A, Gelblum DY, et al. Fatal complications after stereotactic body radiation therapy for central lung tumors abutting the proximal bronchial tree. Pract Radiat Oncol 2016;6:e27-33.

51. Chaudhuri AA, Tang C, Binkley MS, et al. Stereotactic ablative radiotherapy (SABR) for treatment of central and ultra-central lung tumors. Lung Cancer 2015;89:50-6.

52. Raman S, Yau V, Pineda S, et al. Ultracentral tumors treated with stereotactic body radiotherapy: single-institution experience. Clin Lung Cancer 2018;19:e803-10.

53. Chang JH, Poon I, Erler D, et al. The safety and effectiveness of stereotactic body radiotherapy for central versus ultracentral lung tumors. Radiother Oncol 2018;129:277-83.

54. Bezjak A, Paulus R, Gaspar LE, et al. Safety and Efficacy of a Five-Fraction Stereotactic Body Radiotherapy Schedule for Centrally Located Non-Small-Cell Lung Cancer: NRG Oncology/RTOG 0813 Trial. J Clin Oncol 2019;37:1316-25.

55. Tekatli H, Spoelstra FOB, Palacios M, et al. Stereotactic ablative radiotherapy (SABR) for early-stage central lung tumors: New insights and approaches. Lung Cancer 2018;123:142-8.

56. Haasbeek CJ, Lagerwaard FJ, Slotman BJ, et al. Outcomes of stereotactic ablative radiotherapy for centrally located early-stage lung cancer. J Thorac Oncol 2011;6:2036-43.

57. Lambrecht M, Melidis C, Sonke JJ, et al. Lungtech, a phase II EORTC trial of SBRT for centrally located lung tumours - a clinical physics perspective. Radiat Oncol 2016;11:7.

58. Lambrecht M, Clementel E, Sonke JJ, et al. Radiotherapy quality assurance of SBRT for patients with centrally located lung tumours within the multicentre phase II EORTC Lungtech trial: Benchmark case results. Radiother Oncol 2019;132:63-9.

59. Giuliani M, Mathew AS, Bahig H, et al. SUNSET: Stereotactic Radiation for Ultracentral Non-Small-Cell Lung Cancer-A Safety and Efficacy Trial. Clin Lung Cancer 2018;19:e529-e532.

60. Mehta M, Scrimger R, Mackie R, et al. A new approach to dose escalation in non-small cell lung cancer. Int J Radiat Oncol Biol Phys 2001; 49:23-33.

61. Kaster TS, Yaremko B, Palma DA, et al. Radical-intent hypofractionated radiotherapy for locally advanced NonSmall-Cell Lung Cancer: A Systematic review of the literature. Clin Lung Cancer 2015;16:71-9.

62. Fleming C, Cagney DN, O'Keeffe S, et al. Normal tissue considerations and dose-volume constraints in the moderately hypofractionated treatment of non-small cell lung cancer. Radiother Oncol 2016;119:423-31.

63. Thirion P, Holmberg O, Collins CD, et al. Escalated dose for non-small-cell lung cancer with accelerated hypofractionated three-dimensional conformal radiation therapy. Radiother Oncol 2004;71:163-6.

64. Belderbos J, Uitterhoeve L, van Zandwijk N, et al. Randomized trial of sequential versus concurrent chemoradiotherapy in patients with inoperable non-small cell lung cancer (EORTC 08972-22973). Eur J Cancer 2007;43:114-21.

65. Kepka L, Tyc-Szczepaniak D, Bujko K. Dose-perfraction escalation of accelerated hypofractionated three-dimensional conformal radiotherapy in locally advanced non-small cell lung cancer. J Thorac Oncol 2009;4:853-61.

66. Cannon DM, Mehta MP, Adkison JB, et al. Doselimiting toxicity after hypofractionated dose-escalated radiotherapy in non-small cell lung cancer. J Clin Oncol 2013;31:4343-8. 
67. Zhu ZF, Fan M, Wu KL, et al. A phase II trial of accelerated hypofractionated three-dimensional conformal radiation therapy in locally advanced non-small cell lung cancer. Radiother Oncol 2011;98:304-8.

68. Agolli L, Valeriani M, Bracci S, et al. Hypofractionated Image-guided Radiation Therapy (3Gy/fraction) in Patients Affected by Inoperable Advanced-stage Non-small Cell Lung Cancer After Long-term Follow-up. Anticancer Res 2015;35:5693-700

69. Cheung P, Faria S, Ahmed S, et al. Phase II study of accelerated hypofractionated three-dimensional conformal radiotherapy for stage T1-3 N0 M0 non-small cell lung cancer: NCIC CTG BR.25. J Natl Cancer Inst 2014;106:pii:dju 164.

70. Cagney DN, Thirion PG, Dunne MT, et al. A Phase II Toxicity End Point Trial (ICORG 99-09) of Accelerated Dose-escalated Hypofractionated Radiation in Nonsmall Cell Lung Cancer. Clin Oncol (R Coll Radiol) 2018;30:30-8.

71. Bral S, Duchateau M, Versmessen H, et al. Toxicity and outcome results of a class solution with moderately hypofractionated radiotherapy in inoperable Stage III non-small cell lung cancer using helical tomotherapy. Int J Radiat Oncol Biol Phys 2010;77:1352-9.

72. Parisi E, Genestreti G, Sarnelli A, et al. Accelerated hypofractionated radiotherapy plus chemotherapy for inoperable locally advanced non-small-cell lung cancer: final results of a prospective phase-II trial with a long-term follow-up. Radiat Oncol 2019;14:112.

73. Uitterhoeve AL, Belderbos JSA, Koolen MGJ, et al. Toxicity of high dose radiotherapy combined with daily cisplatin in non-small cell lung cancer: results of the EORTC 08912 phase I/II study. Eur J Cancer 2000;36:592-600.

74. Casas F, Viñolas N, Ferrer F, et al. Long-term results of a phase II trial of induction paclitaxel-carboplatin followed by concurrent radiation therapy and weekly paclitaxel and consolidation paclitaxel-carboplatin in stage III non-small cell lung cancer. J Thorac Oncol 2011;6:79-85.

75. Kim JO, Chu KP, Fairchild A, et al. Dose-escalated Hypofractionated Intensity-modulated Radiation Therapy With Concurrent Chemotherapy for Inoperable or Unresectable Non-Small Cell Lung Cancer. Am J Clin Oncol 2017;40:294-9.

76. Koukourakis MI, Patlakas G, Froudarakis ME, et al. Hypofractionated accelerated radiochemotherapy with cytoprotection (Chemo-HypoARC) for inoperable non-small cell lung carcinoma. Anticancer Res
2007;27:3625-31.

77. Cho KH, Ahn SJ, Pyo HR, et al. A Phase II study of synchronous three-dimensional conformal boost to the gross tumor volume for patients with unresectable Stage III non-small-cell lung cancer: results of Korean Radiation Oncology Group 0301 study. Int J Radiat Oncol Biol Phys 2009;74:1397-404.

78. Ren XC, Wang QY, Zhang R, et al. Accelerated hypofractionated three-dimensional conformal radiation therapy (3 Gy/fraction) combined with concurrent chemotherapy for patients with unresectable stage III non-small cell lung cancer: preliminary results of an early terminated phase II trial. BMC Cancer 2016;16:288.

79. Bral S, Duchateau M, Versmessen H, et al. Toxicity report of a phase $1 / 2$ dose-escalation study in patients with inoperable, locally advanced nonsmall cell lung cancer with helical tomotherapy and concurrent chemotherapy. Cancer 2010;116:241-50.

80. Urbanic JJ, Wang X, Bogart JA, et al. Phase 1 study of accelerated hypofractionated radiation therapy with concurrent chemotherapy for stage III Non-Small Cell Lung Cancer: CALGB 31102 (Alliance). Int J Radiat Oncol Biol Phys 2018;101:177-85.

81. Maguire J, Khan I, McMenemin R, et al. SOCCAR: A randomised phase II trial comparing sequential versus concurrent chemotherapy and radical hypofractionated radiotherapy in patients with inoperable stage III NonSmall Cell Lung Cancer and good performance status. Eur J Cancer 2014;50:2939-49.

82. Glinski K, Socha J, Wasilewska-Tesluk E, et al. Accelerated hypofractionated radiotherapy with concurrent chemotherapy for NSCLC: a phase I/II study. Radiother Oncol 2020;148:174-80.

83. Bang A, Bezjak A. Stereotactic body radiotherapy for centrally located stage I non-small cell lung cancer. Transl Lung Cancer Res 2019;8:58-69.

84. Huber RM, Fischer R, Hautmann H, et al. Does additional brachytherapy improve the effect of external irradiation? A prospective study in central lung tumors. Int J Radiat Oncol Biol Phys 1997;38:533-40.

85. Adkison JB, Khuntia D, Bentzen SM, et al. Dose escalated, hypofractionated radiotherapy using helical tomotherapy for inoperable non-small cell lung cancer: preliminary results of a risk-stratified phase I dose escalation study. Technol Cancer Res Treat 2008;7:441-7.

86. Perez CA, Pajak TF, Rubin P, et al. Long-term observations of the patterns of failure in patients with unresectable non-oat cell carcinoma of the lung treated 
with definitive radiotherapy. Report by the Radiation Therapy Oncology Group. Cancer 1987;59:1874-81.

87. Bradley J, Graham MV, Winter K, et al. Toxicity and outcome results of RTOG 9311: a phase I-II doseescalation study using three-dimensional conformal radiotherapy in patients with inoperable non-smallcell lung carcinoma. Int J Radiat Oncol Biol Phys 2005;61:318-28.

88. Rosenzweig KE, Fox JL, Yorke E, et al. Results of a phase I dose-escalation study using three-dimensional conformal radiotherapy in the treatment of inoperable nonsmall cell lung carcinoma. Cancer 2005;103:2118-27.

89. Kong FM, Hayman JA, Griffith KA, et al. Final toxicity results of a radiation-dose escalation study in patients with non-small-cell lung cancer (NSCLC): predictors for radiation pneumonitis and fibrosis. Int $\mathrm{J}$ Radiat Oncol Biol Phys 2006;65:1075-86.

90. Belderbos JS, Heemsbergen WD, De Jaeger K, et al. Final results of a Phase I/II dose escalation trial in nonsmall-cell lung cancer using three-dimensional conformal radiotherapy. Int J Radiat Oncol Biol Phys 2006;66:126-34.

91. Belderbos JS, Kepka L, Kong FM, et al. Report from the International Atomic Energy Agency (IAEA) consultants' meeting on elective nodal irradiation in lung cancer: nonsmall cell lung cancer (NSCLC). Int J Radiat Oncol Biol Phys 2008;72:335-42.

92. van Baardwijk A, Wanders S, Boersma L, et al. Mature results of an individualized radiation dose prescription study based on normal tissue constraints in stages I to III non-small-cell lung cancer. J Clin Oncol 2010;28:1380-6. 93. van Baardwijk A, Reymen B, Wanders S, et al. Mature

Cite this article as: Kepka L, Socha J. Dose and fractionation schedules in radiotherapy for non-small cell lung cancer. Transl Lung Cancer Res 2021;10(4):1969-1982. doi: 10.21037/ tlcr-20-253 results of a phase II trial on individualised accelerated radiotherapy based on normal tissue constraints in concurrent chemo-radiation for stage III non-small cell lung cancer. Eur J Cancer 2012;48:2339;46.

94. De Ruysscher D, van Baardwijk A, Wanders R, et al. Individualized accelerated isotoxic concurrent chemoradiotherapy for stage III non-small cell lung cancer: 5 -Year results of a prospective study. Radiother Oncol 2019;135:141-6.

95. Hallqvist A, Bergström S, Björkestrand H, et al. Dose escalation to $84 \mathrm{~Gy}$ with concurrent chemotherapy in stage III NSCLC appears excessively toxic: Results from a prematurely terminated randomized phase II trial. Lung Cancer 2018;122:180-6.

96. Fenwick JD, Landau DB, Baker A, et al. Long-term results from the IDEAL-CRT phase 1/2 trial of isotoxically doseescalated radiation therapy and concurrent chemotherapy for stage II/III non-small cell lung cancer. Int J Radiat Oncol Biol Phys 2020;106:733-42.

97. Barrett S, Hanna GG, Marignol L. An overview on personalisation of radiotherapy prescriptions in locally advanced non-small cell lung cancer: Are we there yet? Radiother Oncol 2018;128:520-33.

98. Roach MC, Bradley JD, Robinson CG. Optimizing radiation dose and fractionation for definitive treatment of locally advanced non-small cell lung cancer. J Thorac Dis 2018;10:S2465-73.

99. Antonia SJ, Villegas A, Daniel D, et al. Overall survival with Durvalumab after chemoradiotherapy in stage III NSCLC. N Engl J Med 2018;379:2342-50. 